\title{
Iranian scholar sentenced to death
}

Ahmadreza Djalali, a researcher in disaster medicine, has 20 days to appeal against his death sentence.

\section{Michele Catanzaro}

23 October 2017

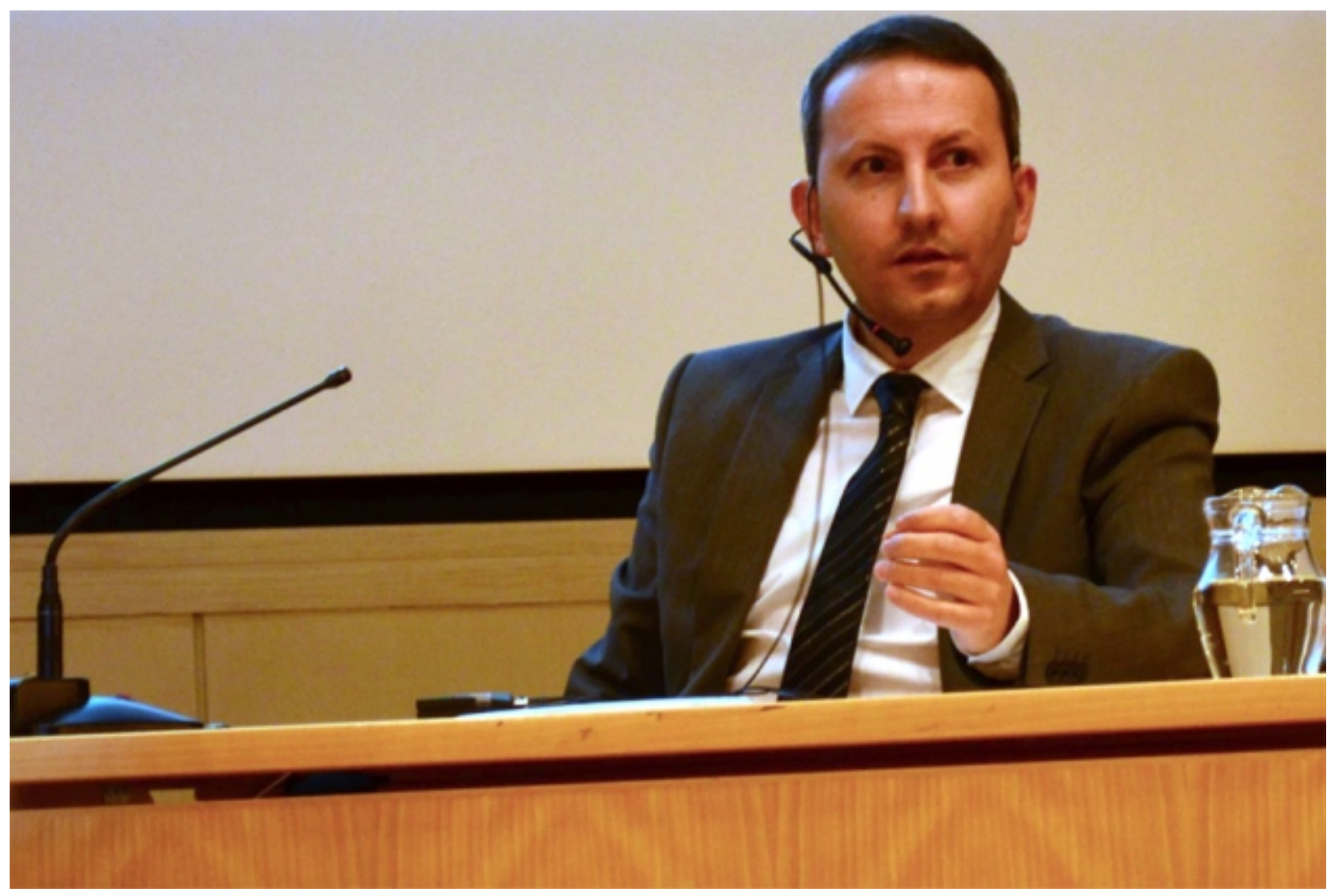

Courtesy of Vida Mehrannia

Researcher Ahmadreza Djalali was convicted of espionage and sentenced in Iran on 21 October.

A judge in Tehran has ordered the death penalty for Iranian researcher Ahmadreza Djalali, according to his wife and diplomatic sources in Italy.

Djalali is affiliated with the Karolinska Institute in Stockholm, Sweden, and the University of Eastern Piedmont in Novara, Italy. A resident of Sweden with his family, Djalali was arrested in April 2016 on an academic visit to Tehran and accused of "collaboration with a hostile government". He works on 
improving hospitals' emergency responses to armed terrorism and radiological, chemical and biological threats.

Djalali was convicted of espionage following a trial led by Abolqasem Salavati, a judge in Iran's revolutionary court, and sentenced to death on 21 October, according to Djalali's wife Vida Mehrannia and to Italian diplomatic sources. They say he has 20 days to appeal against the sentence.

Mehrannia says that her husband was accused of obtaining money, academic positions and research projects in exchange for spying on Iran for Israel.

\section{Djalali document}

Shortly before the sentence was announced, a close contact of Djalali's (who would prefer to remain anonymous) circulated a document

\section{Related stories}

- Iranian scientist to go on trial for espionage

- Jailed Iranian researcher's health worsening rapidly

- Iran releases physicist after five years in jail

\section{Related stories}

- Iranian scientist to go on trial for espionage

- Jailed Iranian researcher's health worsening rapidly

- Iran releases physicist after five years in jail

that claims to be a literal transcription of a handwritten text produced by Djalali inside Evin prison, where he is being held. The document states that Djalali believes he was arrested for refusing to spy for the Iranian intelligence service.

According to the document, in 2014 two representatives of the Iranian military and intelligence service asked Djalali to spy on European countries for Iran - in particular, on "critical infrastructures, counterterrorism and CBRNE [chemical, biological, radiological, nuclear and explosives] capabilities, sensitive operational plans, and also research projects, relevant to terrorism and crisis." It says he refused.

The document claims that Djalali was forced to make false confessions following "multiple psychological and physical tortures". "I have never acted against my country, I have never spied for Israel or any other country. My only fault is that I did not accept to use the trust of my colleagues and universities in EU to spy for Iran's intelligence services," the text states.

Djalali's colleagues have reacted with dismay. "None of our shared research projects had partners in Israel and I am not aware of any money transfer from Israel to Djalali. We relied on European Commission funds," says Luca Ragazzoni, a health researcher at the University of Eastern Piedmont, who worked with Djalali from 2012 to 2015 . "We did not have access to secret data," he says. 
Mehrannia says that Djalali is considering a hunger strike in protest at the sentence. Since his imprisonment, Djalali has carried out multiple hunger and thirst strikes. He was also forced to change his lawyer against his will, according to the Committee of Concerned Scientists, a lobby group. Several scholars and human-rights organizations have repeatedly called for a fair trial or release for Djalali.

Djalali's story echoes those of other Iranian scientists. Omid Kokabee, a physicist released from a Tehran jail in August 2016 after five years' imprisonment, says he believes he was punished for refusing to help a covert nuclear-weapons programme. Hamid Babaei, who was undertaking a PhD in finance in Belgium but is now serving a six-year prison sentence in Iran, has said he was arrested for refusing to spy on his colleagues.

Nature doi:10.1038/nature.2017.22875 